\title{
DesignBuildBLUFF: Coyote architecture on the Colorado Plateau
}

\author{
J. Murray ${ }^{1}$, R. Sommerfeld ${ }^{2}$, G. Longhurst ${ }^{1}$, C. Bithell ${ }^{3}$, \\ C. Wilson ${ }^{3}$, A. Yamamoto ${ }^{3}$, H. Ogiso ${ }^{3}$, A. Bradshaw ${ }^{3}$, \\ H. Louis ${ }^{3}$, D. Penny ${ }^{1}$ \& D. Young ${ }^{1}$ \\ ${ }^{1}$ Integrated Engineering Department, Southern Utah University, USA \\ ${ }^{2}$ College of Architecture, University of Colorado, USA \\ ${ }^{3}$ DesignBuildBLUFF, USA
}

\begin{abstract}
The Four Corners region, located in the heart of the Colorado Plateau, is a land of little rain, sparse vegetation, extreme climate, and vivid landscapes. It is considered by the Diné (Navajo) to be a sacred place. Intimate connections between earth, water, and sky are gradually revealed to plateau dwellers with open hearts and seeing eyes. In this inspiring setting, DesignBuildBLUFF (DBB), a non-profit founded by architect Hank Louis, provides sustainable, pro bono homes for Navajo families on the reservation near Bluff, Utah. Architecture students from the University of Utah, the University of Colorado, Denver, and engineering students from Southern Utah University design the experimental homes during the summer or fall semester, and build the homes the following semester. DBB students blend qualities of the artist, the jester, and the sage with a fierce work ethic and a passionate desire to design and build something real. Glimpsed fleetingly at dawn en route to the building site or returning home at dusk to Bluff, the roughly clad, wildly inventive students might easily be mistaken for coyotes, Canis latrans, pursuing prey. This paper describes how students participating in DesignBuildBLUFF 2012 created Raine House, a 1,200 square foot, passive solar home for Lorraine Toney and her five children. EnergyPlus and OpenStudio software from the National Renewable Energy Laboratory were used in the design of Raine House, connecting contemporary science to the ancient architectural triad of firmness, commodity, and delight.

Keywords: passive solar, Native American, sustainable, pro bono, design-build.
\end{abstract}




\section{Introduction}

Sustainability on the Colorado Plateau has changed over the last ten thousand years as a result of variations in climate, human and animal migrations, and recent advances in science and technology. During the last two centuries, the discovery of mineral resources, the industrial revolution, formal education, modern medicine, exponential population growth, overgrazing by sheep and cattle, human conflict, the introduction of a fossil fuel-dependent market economy, the expansion of outdoor recreation, and anthropogenic climate change have influenced regional sustainability in both positive and negative ways. The creation of sustainable homes in this region offers one way in which the lives of indigenous people and those of modest income can be markedly improved. Raine House, an example of this design philosophy, is illustrated in Figure 1.

Larger, systemic questions naturally arise in this shifting environment, including, "Is humanity a part of nature, or can it stand apart, defining the form and function of the planet over the long term?" "Is it possible to create sustainable communities in a region in which desertification, reduction in winter snowpack levels, and earlier spring runoff are taking place?" and "What forms of ecosystem restoration are possible, and to what state, given the rapidly evolving setting? Also, due to the great distances between small-scale plateau communities and cities where viable employment is available, long commutes, often exceeding 100 miles per day, are common. Substantial quantities of increasingly expensive, carbonemitting fossil fuels are currently consumed as a result. Can a distributed economy evolve in this lovely, dynamic region that encourages the transition from fossil fuels to renewable energy sources, develops mass transportation systems, participates collectively in large-scale ecosystem restoration activities, and focuses on the creation of small-to medium scale public and private-sector enterprises? All this hinges, of course, on the existence of affordable educational opportunities, appropriate subsidies, the necessary supporting infrastructure, and the transformation of human perceptions. Awareness of these questions, seen through the lens of many cultures, human and non-human alike, is central to the DesignBuildBLUFF experience. Samuel Mockbee, the founder of Rural Studio at Auburn University, captured the spirit of similar pro bono design/build projects that he and his students launched along the Mississippi/Alabama border. He said "it was a lot like being snakebit."

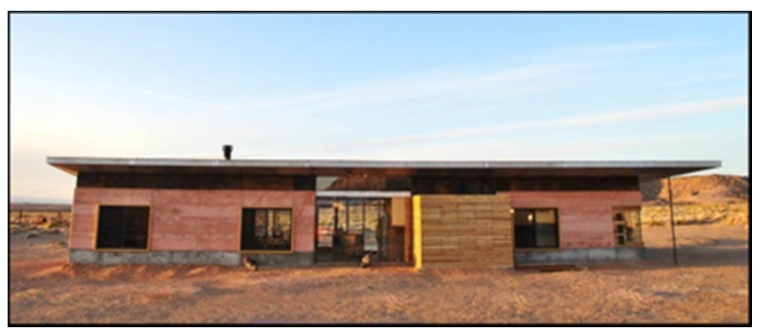

Figure 1: Raine House, passive solar home, Navajo Nation. 


\section{DesignBuildBLUFF 2012: a guided tour}

The DesignBuildBLUFF [1] Project's system boundaries were defined by student creativity, physical and financial resources, time, and personal energy. Students were expected to be self-directed, perform as team players, be experimentally focused, be capable of independent research, raise questions, and remain undaunted by complex, ongoing challenges. DesignBuildBLUFF is, according to Professor Rick Sommerfeld, "What you make of it." "Everyone, from all backgrounds and interest areas, can speak up and be heard. There are no dumb questions, only unasked questions. You run your own play." Professor John Murray suggested, "It is a place to expand your circle of understanding and action, a source of illumination, an opportunity to know yourself, and a time to interact closely with another culture."

\subsection{DesignBuildBLUFF: summer design session in Denver, Colorado}

The summer semester in Denver focused exclusively on design work. An initial site visit and client interview, essential for pre-design and architectural programming activities, took place May 15-17, 25 miles from Bluff, on the Navajo reservation. Students and faculty subsequently returned to Denver, participated in weekly studio sessions, and worked independently in small groups between studios. They applied knowledge acquired in the following disciplinary areas: architecture (design of the home), mathematics, physics, and heat transfer (passive heating and cooling calculations and simulations), fluid mechanics (passive cooling calculations and piping design), structural analysis (structural integrity of the home), strength of materials and concrete and steel (foundation, wall, and roof design), electric circuits (electrical wiring), CAD (architectural and engineering drawings), economics (cost estimation), and writing (general communication, final report), and construction techniques (on-site construction work).

The students iterated through twenty-two unique design ideas related to groupdefined first principles before arriving at a final design, accomplishing this feat with great panache and little observed bloodshed. Schematic design and design development work were completed in studio by June 29th. Presentation of the initial design (drawings, renderings, and basswood model) to Lorraine and her family occurred July 5-8 in Bluff. Additional design development work and modifications based on direct client feedback took place July 9-26. Representative examples of Raine House interior spaces are shown in Figure 2.

\subsection{DesignBuildBLUFF: Fall build session in Bluff, Utah}

The fall semester in Bluff focused on construction work at the remote building site, twenty-five miles away on the Navajo reservation. Construction began on August 14, and was completed on December 14. Students self-organized into twenty-two groups to complete the construction work, with each student having the opportunity to lead a group, and participate in three to four additional groups. 
The construction groups included: project schedule, framed walls, master bathroom, record drawings, roof, children's bedrooms, client contact, night insulation (sliding panels), living room/kitchen, budget, windows, electrical system, construction documents, doors, plumbing system, foundation, children's bath/utility area, heating, concrete walls, master bedroom, cooling, and deck.

During the fall, students worked from dawn to dusk six days per week, often followed by meetings well into the night. Work was organized into two-week sessions or "blocks," with one "off" week between sessions. "Off" weeks were spent doing optional design and construction work, exploring Anasazi (Ancestral Puebloan) sites, traveling, hiking, biking, swimming in the adjacent San Juan River, or simply resting.

Students, instructors, and construction professionals lived in an eclectic assortment of dwellings on the Bluff campus. In addition, a wood and metal fabrication shop, an outdoor storage space for building materials, and a commons area were located on the campus. Rotating groups of 2-3 students prepared meals and cleaned up nightly, traveling weekly for groceries to Blanding, Utah (25 miles) or Cortez, Colorado (50 miles) since the population of Bluff, Utah (200-300 residents), does not justify a high volume, low cost food outlet. Acquiring building supplies required extensive travel and advance planning as well. Chores around the Bluff campus were also performed by the students.
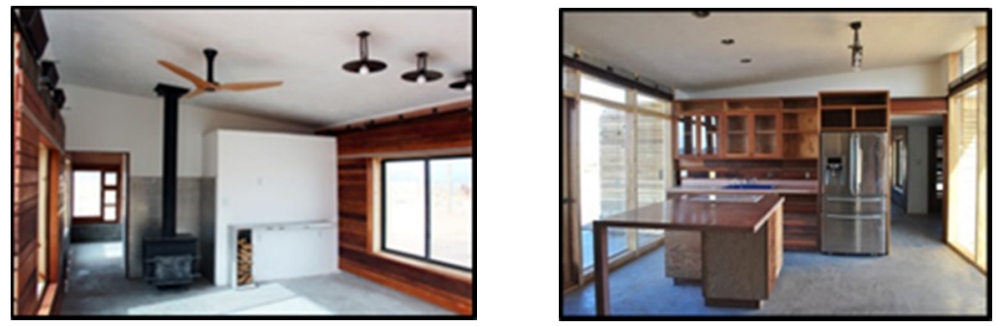

Figure 2: $\quad$ Great room (left), kitchen and dining area (right).

\section{Cultural context: Coyote voices, the Navajo worldview, and sustainable design}

Historian J. Frank Dobie, in The Voice of the Coyote [2], portrayed Canis latrans in a Navajo context, "The coyotes have been telling the Navajo Indians something glad. The Yebichi dance that they chant in the fall is the "dawn child's" song of happiness: "Just when morning is coming on I give my call...Right out of my mouth I call. By means of darkness I call. I call when it is quite dark. With the aid of my tail I call. At dawn, you know also, I call. At sunrise I call." Ethnomusicologist Joshua Veltman [3] states that the overriding purpose of the Yebichi dance, an essential part of the Chantway Ceremonials, is to restore hózhó [4]. Witherspoon and Peterson in Dynamic Symmetry and Holistic Asymmetry in Navajo and Western Art and Cosmology [5] state that "For the Navajo, hózhó expresses the intellectual notion of order, the emotional state of happiness, the 
physical state of health, the moral condition of good, and the esthetic dimension of harmony...Hózhó is the grand metaphor by which the Navajo understand the world and their place in it." Over the course of the Raine House project, as DesignBuildBLUFF students worked with client Lorraine Toney and her family to determine their housing, landscape, energy, water, and transportation needs, key elements of hózhó, the Dine' traditional living system, a comprehensive system which places life in harmony with the natural world and the universe, came to influence the design and construction process and give it deeper meaning. Careful listening, close observation, being open to new ideas in an unfamiliar cultural and physical context [6-7], and humor allowed the students to develop a sense of place, understand their client's programming requirements, and, like wild, unfettered coyotes, raise their architectural and engineering voices in song.

\section{Raine House: site visit and client interview}

Exhibiting enthusiasm, good will, and an understandable nervousness about working on a real project to be completed within budget, on schedule, and for a client from another culture, twenty architecture graduate students from the University of Colorado, Denver, and two senior engineering students from Southern Utah University traveled May 17-20 to the Four Corners area, accompanied by two faculty members, John Murray and Rick Sommerfeld, to meet with client Loraine Toney on land her family had been assigned by the Navajo tribe in the Red Mesa District of the reservation, twenty five miles southeast of Bluff, Utah. The tribe had previously selected her from among several applicants for a DBB home. The objective of the visit was to determine her family's housing needs and do a site survey. When the crew arrived, the DesignBuildBLUFF staff introduced us to Lorraine and her extended family, including her parents and children. During the first hour, they told us stories about themselves and the land. Lorraine mentioned that although she was modern in outlook and in her daily activities, she was also traditional in many important ways. She also told us she commuted sixty miles each way to work in Shiprock, New Mexico, but hoped to find work closer to home in the future. We then shared stories about ourselves, and began a basketball game with her children.

Determining the client's needs, i.e. defining the formal program, involved asking Lorraine what features she would like in her new home. During the informal, outdoor interview, she said she would like the following: A house for her and her five children, since they have no suitable place to live; an open floor plan to allow free circulation within the house; shelter from the strong prevailing winds and blowing sand; a shared room for the girls; a shared room for the boys; a room for herself; a great room combing living and dining spaces; adequate storage space; a full bath plus a half-bath; windows that allow her to watch her children outside and view the landscape; a deck that would allow her family to spend time outside comfortably; no exposed hot surfaces for child safety; a sheltered exterior space for a garden and trees; an outdoor fire pit for cooking, gatherings, and ceremonies; a kitchen with a propane stove, since electricity is sometimes unreliable, and gas is available locally; an entrance facing east, toward 
the rising sun (Diné traditional practice); access to water and electricity via the tribal utility; and restoration of the deteriorating school bus stop nearby.

In addition, we discussed including windows to provide views of the four mountains sacred to the Diné; orientation of the house and the inclusion of thermal mass to allow passive heating and cooling via sun and wind; insulation and shading structures to minimize energy consumption; selecting the color of the walls and roof to harmonize the house with the landscape; the precise siting of the house on the largely flat, overgrazed, desert landscape populated by yucca, blackbrush, ephedra, and bunch grasses; geotechnical issues, which proved to be minimal; and overall system maintenance, which should be kept to a minimum.

\section{The integrated design process: a detailed view}

Integrated design is a process in which architects, engineers, and construction professionals work creatively [8-10], synergistically, and efficiently during all stages of the design cycle to create cost effective, resilient, sustainable environments for their clients. This process was determined to be a key focus of DesignBuildBLUFF 2012. Two engineering seniors from Southern Utah University were included in DBB for the first time. The intent was that the engineering students would work closely with the architecture students to achieve an energy efficient design. Rather than working separately within their own disciplines, and periodically consulting with each other while struggling for an optimum outcome, all DBB students joined together in the Denver studio to exchange design ideas and learn from each other directly throughout the entire semester. Theoretical calculations and software simulation tools, including EnergyPlus and Open Studio, produced by the National Renewable Energy Laboratory (NREL) [11], and SketchUp, produced by Google, were used to create a passive, direct gain solar architecture capable of maintaining internal temperature swings in the home within acceptable limits over the course of a typical meteorological year, with little or no fossil fuel energy required for heating or cooling. Simulated winter temperature variations ranged from $62^{\circ} \mathrm{F}\left(16.7^{\circ} \mathrm{C}\right)$ to $57 \mathrm{~F}\left(13.9^{\circ} \mathrm{C}\right)$ from day to night. Simulated summer temperature variations ranged from $79 \mathrm{~F}\left(26.1^{\circ} \mathrm{C}\right)$ to $70 \mathrm{~F}\left(21.1^{\circ} \mathrm{C}\right)$ from day to night, assuming no night cooling through open windows, which is common practice in the region, due to the exceptionally dry climate.

Creating a passive house to satisfy the desired program at minimal cost initiated experimentation with a range of "box" and "bar" shaped architectural spaces, yielding an east-west orientation for the long axis of the home, with large windows included on the south face (approximately $20 \%$ of floor area) for solar gain. Sliding interior panels incorporating R10 night insulation were included to minimize heat loss through the two largest windows during the winter months.

The building envelope included vertical walls which sandwiched four inches of extruded polystyrene insulation (R20) between six inches of concrete on the interior, and three inches of concrete on the exterior. Including local, colored sands in the concrete allowed the walls to blend with the surrounding terrain. A 
four inch, exposed, steel-reinforced slab and a frost-resistant footer with R10 peripheral insulation were also included. A vertical wall is illustrated in Figure 3.

The walls, slab, and footer provided considerable thermal mass, essential for absorbing and re-radiating energy in this passive design. Fiberglass batt insulation (R30) was used between the wooden, engineered I-beams supporting the OSB and the corrugated, corten steel roof structure. Batt insulation was also used in the entry way and window structures extending outward from the bedroom areas. Dimensioned lumber was also included to provide structural integrity for the roof in selected spaces. A backup woodstove was provided to assure thermal comfort in exceptional, worst-case winter weather conditions. Propane gas (LP) was chosen for cooking. Budgetary considerations and access to nearby electricity precluded the incorporation of an on-grid solar photovoltaic system, although panels can be added on the roof in the future, if desired.

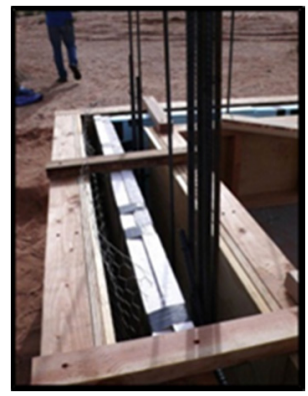

Figure 3: Vertical wall.

\subsection{Design studio activities}

Work in the design studio was launched based on concepts discussed on the Bluff Campus following the site visit and client interview in May. Prior to arriving in studio in June, students began developing areas of interest in the architecture, engineering, and construction aspects of the house. Exploring a spectrum of ideas and interests including materiality, passive design, unconventional construction techniques, simplicity in design, maintenance, removal of the distinction between indoors and outdoors, modularity, net zero energy design, hands-on construction experience, appropriate finishes, cultural considerations, tailoring the home to the client, flexible spaces, and survivability. In June, students, with twenty-two unique design ideas in mind converged on the Denver studio, and quickly merged into smaller, three to five person groups, with each group having self-selected common areas of interest. Thinking and sketching began in earnest. The fundamental idea was to iteratively select and combine the best ideas from each group's design into a new form, a superior synthesis, and subsequently compare and critique the emerging design individually, communally, and continuously. Spaces, features, materials, and esthetics began to mix, come apart, and coalesce almost magically. Throughout the month of June, while experimenting and learning at a furious pace, sleeping little, iterating through countless drawings, tracings, and basswood 
models, running energy simulations (which caused additional design iterations), and generally having a good time, the designers wove their work into a tentative architectural tapestry, the first version of Raine House. Additional iterations occurred between June 29th and August 15th, when construction began, and continued through December 14th, when the house was completed and became available for occupancy. The plan view (floor plan) for Raine House is provided in Figure 4.

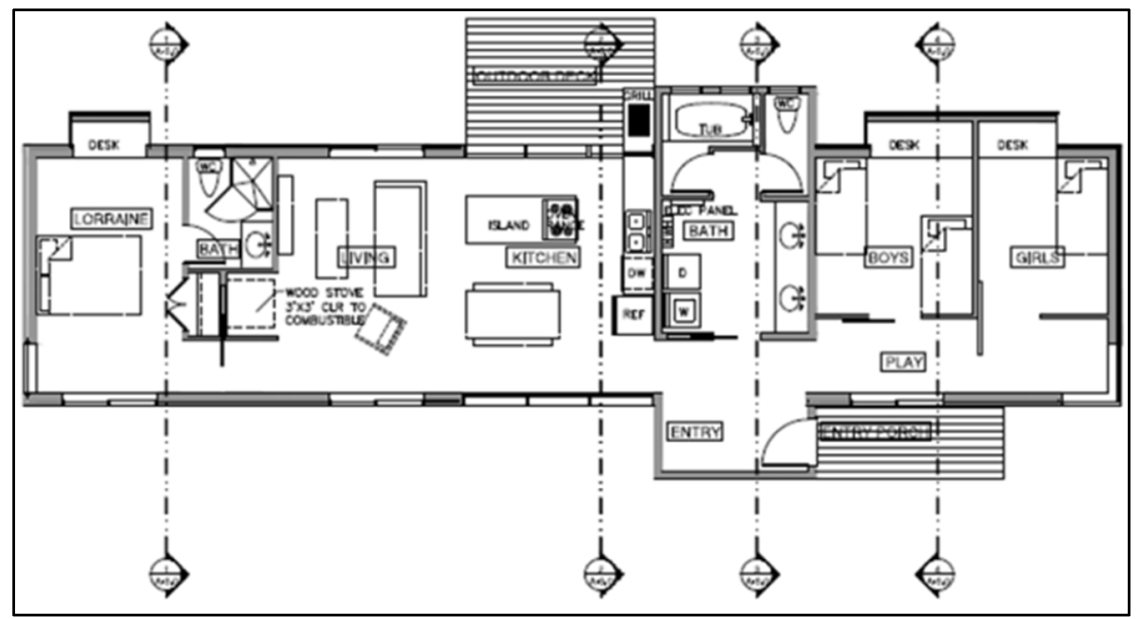

Figure 4: Raine House plan view (floor plan).

\subsection{Design description}

The westernmost segment of the house consists of a private space created for Lorraine. It includes room for a bed, a small bathroom with shower, an enclosed storage area, bookshelves, and a built-in desk facing a wall paneled with richly hued, horizontal wood planking, flanked by narrow, vertical, east and westoriented windows, which allow daylight to illuminate the desks' working surface with minimal glare. A large window on the south side of the space provides solar gain in winter. On the south face of the house, the overhanging roof acts as a shading structure to minimize light entry during summer months. A smaller window on the west, eventually to be shaded by vegetation, permits low angle afternoon sunlight and light reflected off the desert sand to penetrate the room.

The great room, defining the center portion of the home, contains a woodstove, space for a couch, chair, table, dining room furniture, and a portable food preparation island, including the primary cooking surface plus storage space for a propane tank. Sinks, counter space, custom mahogany cabinetry, and nooks for a dishwasher and refrigerator are located on the east end of the great room. A large, glass curtain wall and adjacent door on the north side of the room provide an 
expansive view of the mountains in the distance, and overlooks an exterior deck and masonry fire pit. On the south side of the room, extensive glass provides significant solar gain during winter. In order to retain heat within interior thermal mass after sunset in winter, the two largest north and south facing glass areas can be covered by sliding wooden panels incorporating R10 night insulation. The panels can also be used to minimize heating during the early morning and late afternoon hours on exceptionally bright, clear days occurring anytime during the year. The primary circulation path runs along the south side of the house, passing from Lorraine's bedroom, through the great room, near the east-facing entryway, past the children's bath area, and into the children's bedroom area. Another perpendicular pathway can be seen to run from the small exterior deck adjacent to the entryway heading northward toward the door adjacent to the curtain wall, and out onto the large deck.

Optimal provision of bathroom space for Lorraine's five children was a key ingredient in the Raine House design. Immediately to the east of the great room, a module containing several small spaces was created to allow private access to the water closet, bathtub/shower area, and dual sink. The ability for several children to use these separate areas simultaneously should reduce congestion in the morning and evening. The same module also includes spaces for a washer, dryer, hot water heater, storage cabinets, and electrical panel.

In the easternmost segment of the house, spaces provided for sleeping and doing homework for the boys and girls are similar in concept to the compact sleeping nooks experienced by blue water sailors in ocean-going yachts. In addition to sleeping, the nooks provide storage lockers, built-in desks, bookshelves, and windows similar to those found in their mother's bedroom. A common play area is located immediately outside the private nooks.

\subsection{Design presentation to client}

On July 5, DBB students travelled from Denver to Bluff. Lorraine and her extended family dined with the DBB crew on the Bluff Campus. Following food and social interaction at the historic Scorup House located on campus, Raine House drawings and a basswood model were presented to the family. Joy, amazement, and gratitude were the overriding emotions expressed. Suggested design modifications were later incorporated.

\section{Raine house construction process}

Construction began on August 14th. Instruction on safety and the use of small power and hand tools was provided. Students worked at the building site in pairs for safety due to the remote location and the lack of nearby major medical facilities. The foundation, plumbing, and electrical trenches were dug by hand. Concrete was prepared using a powered mixer. Materials were generally transported by pickup truck. A licensed structural engineer, Andy Paddock, provided pro bono consulting on the structure. Construction was completed on December 14th. Lorraine and her family moved into the house shortly thereafter. 
A collage of photographs showing construction, recreation, and social activities is presented in Figure 5.

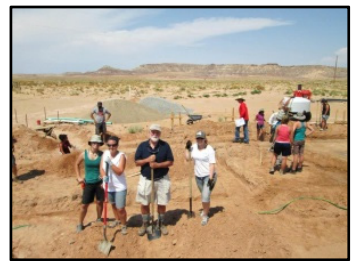

Site Excavation $8 / 17$

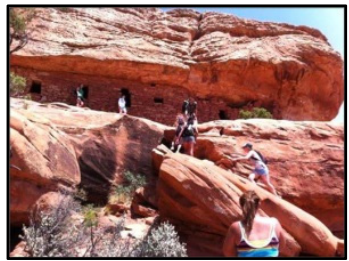

Cliff Dwellings 8/25

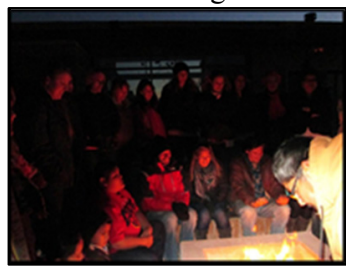

Medicine Man 12/9

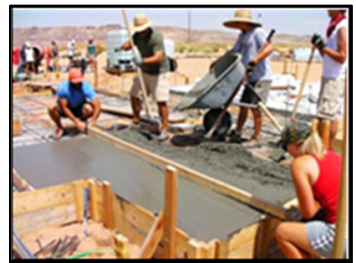

Concrete Finishing 8/21

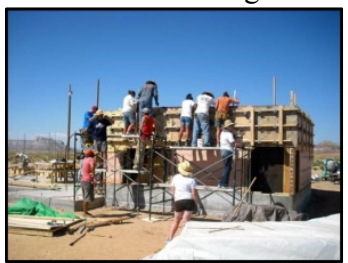

Pouring Red Wall 9/24

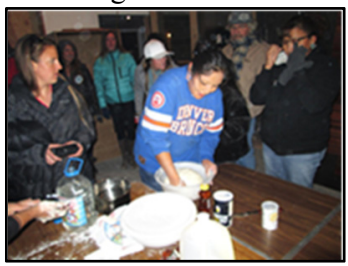

Making Fry Bread 12/9

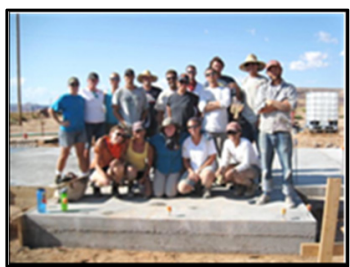

Foundation $8 / 24$

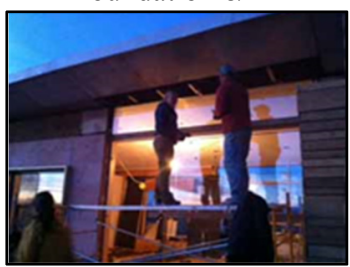

North Curtain Wall 12/7

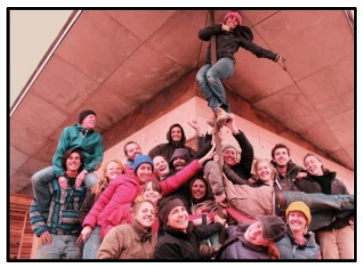

DBB Crew 12/14

Figure 5: Construction, recreation, and social activities.

Completion of the house provided an opportunity for celebration. Miss Navajo Nation sang several songs outside the house. A Medicine Man later offered a prayer of thanks, chanting over the fire pit constructed adjacent to the north deck. Lorraine, our client, then taught the entire DBB crew how to make Fry Bread.

\section{Conclusions}

Raine House was intended to provide a custom, low-cost solution to our client's needs. It succeeded, with few flaws. An example of regional modernism, the house was described as "a magnificent fit to the environment and culture of the region." Performance assessment may suggest similar solutions for others. Raine House, similar in area to Solar Decathlon homes, was built on a smaller budget. It also contrasts with Habitat for Humanity homes since the designs are experimental, and fit the climate, landscape, and locally available materials.

Working with the National Renewable Energy Laboratory (NREL), proved gratifying. We were able to employ their latest energy modeling software in the design and simulation of Raine House immediately after each version was released. Support from NREL was exceptional when questions arose. 
Upon completion of the project, DesignBuildBLUFF students were asked to reflect on their experiences. An outcome expressed by many students indicated they had gained confidence in their ability to actually create elegant, low-cost, client-centered architecture and physically implement it in a timely manner. In addition, they were grateful for having the opportunity to work with people from another culture toward a mutual goal. Many students indicated that the process had been one of the most rewarding experiences of their entire lives.

In the spring of 2013, Raine House received the 2013 AIA (American Institute of Architects) Colorado YAAG People's Choice Award.

\section{The way forward}

To achieve sustainability as defined by the Brundtland Commission [12], ecologists Howard and Eugene Odum [13], and the Club of Rome's "Limits to Growth" authors [14], we must look toward future generations, integrating the arts and the sciences as suggested by C.P. Snow [15]. This implies not only creating sustainable buildings but transforming cultures. Practitioners from additional disciplines might be profitably integrated into the already diverse DesignBuildBLUFF talent mix.

A Native American proverb suggests that, "A people without history is like the wind on the buffalo grass. The wind blows, and the grass bends." A plausible historical framework for the continuing evolution of DesignBuildBLUFF can be found in the life of Petrarch [16-17], the Italian humanist and first modern scholar. In April of 1336, Petrarch, a noted poet and minor cleric, ascended Mount Ventoux near Marseilles. While resting near the summit, viewing the Rhone River and the Cevennes Mountains in the distance, and reflecting on their beauty, Petrarch opened a copy of St. Augustine's Confessions and read, "And men go about to wonder at the heights of the mountains, the mighty waves of the sea, the wide sweep of rivers, the circuit of the ocean, and the revolution of the stars, but themselves they consider not." Reflecting on these lines during his descent, he may have realized that what was inside himself was just as beautiful as everything around him and, in the process, reaffirmed the immense power of the human imaginative faculty, a vision in stark contrast with Medieval perceptions of man as a lowly, errant being. As a result of his travels, writings, and efforts to encourage the reading of classical texts recently made available following centuries of obscurity, the poet Petrarch was recognized as one of the first humanists, and a key driver of the Italian Renaissance. The architectural poets of DesignBuildBLUFF, working in concert with Margaret Mead's "small groups of thoughtful, committed citizens," may also be introducing a paradigm to the world, that of affordable, architecturally desirable, energy efficient dwellings, eminently suited for sustainable living.

\section{Acknowledgements}

The twenty-two students participating in DesignBuildBLUFF 2012 were: B. Majerus, C. Hoffman, C. Cherry, E. Mascitelli, H. Hagenau, J. Astorino, K. 
Derhammer, L. Mears, L. Peterson, L. Watkins, L. Hollm, Lindsay Moore, M. Hattman, M. Tervort, M. Brown, M. C. Burns, M. Brankamp, M. Campagna, R. Sockwell [TA], S. Zezulka, S. Boman, T. Jorfald, and T. Villasenor.

The budget for Raine House, including contributions from the Navajo Tribe and donations from private and public sector sources totaled approximately $\$ 30,000$. Supplementary building materials valued at approximately $\$ 10,000$ were provided by Big D Construction Corporation, Salt Lake City, Utah. Visual Analysis, an $\$ 11,000$ structural analysis software package, was provided by IES Inc., Bozeman, Montana. Additional materials were scavenged or recycled from various sources, including the material storage "boneyard" located on the DesignBuildBLUFF campus in Bluff, Utah.

\section{References}

[1] DesignBuildBLUFF, http://designbuildbluff.org/

[2] Dobie, J. F., The Voice of the Coyote, Bison Books, Lincoln, 2006.

[3] Veltman, J., Nightway Yeibichai Songs and the Navajo Worldview, Ph.D. Candidacy Exam Essay, Ohio State University, 2001.

[4] Farella, J. R., The Main Stalk: A Synthesis of Navajo Philosophy, University of Arizona Press, Tucson, 1990.

[5] Witherspoon, G., \& Glen Peterson, G. Dynamic Symmetry and Holistic Asymmetry in Navajo and Western Art and Cosmology, Peter Lang, New York, 1995.

[6] Iverson, P., \& Roessel, M., Diné: A History of the Navajo, University of New Mexico Press, Albuquerque, 2002.

[7] Collier, M., Water, Earth, and Sky: The Colorado River Basin, University of Utah Press, Salt Lake City, 1999.

[8] Koestler, A., The Act of Creation, Macmillan, London, 1964.

[9] Grudin, R., The Grace of Great Things: Creativity and Innovation, Mariner Books, Boston, 1991.

[10] Weisman, A., Gaviotas: A Village to Reinvent the World, Chelsea Green, White River Junction, Vermont, 1998.

[11] National Renewable Energy Laboratory (NREL), http://www.nrel.gov/

[12] Brundtland Report, http://www.un-documents.net/our-common-future.pdf

[13] Odum, H. T., Environment, Power, and Society for the Twenty-First Century, Columbia University Press, New York, 2007.

[14] Meadows, D. H., Meadows, D. L. \& Randers, J. Limits to Growth: The 30Year Update, Chelsea Green, White River Junction, Vermont, 2005.

[15] Snow, C. P., The Two Cultures, Cambridge University Press, Cambridge, 2012.

[16] Robinson, J, \& Rolfe, H., Petrarch, the First Modern Scholar and Man of Letters, University Press of the Pacific, Honolulu, 2003.

[17] Medieval Sourcebook, http://www.fordham.edu/halsall/source/petrarchventoux.asp 